\title{
Utilisation Trend of Long-Acting Insulin Analogues including Biosimilars across Europe: Findings and Implications
}

\author{
Brian Godman ${ }^{(D)},{ }^{1,2,3}$ Magdalene Wladysiuk, ${ }^{4,5}$ Stuart McTaggart, ${ }^{6}$ Amanj Kurdi ${ }^{1 D},{ }^{1,2,7}$ \\ Eleonora Allocati, ${ }^{8}$ Mihajlo Jakovljevic ${ }^{(D)},{ }^{9,10}$ Francis Kalemeera ${ }^{(D)},{ }^{11}$ Iris Hoxha, ${ }^{12}$ \\ Anna Nachtnebel, ${ }^{13}$ Robert Sauermann, ${ }^{13}$ Manfred Hinteregger, ${ }^{13}$ \\ Vanda Marković-Peković ${ }^{D},{ }^{14}$ Biljana Tubic, ${ }^{15,16}$ Guenka Petrova, ${ }^{17}$ \\ Konstantin Tachkov ${ }^{D},{ }^{17}$ Juraj Slabý, ${ }^{18}$ Radka Nejezchlebova, ${ }^{18}$ Iva Selke Krulichová, ${ }^{19}$ \\ Ott Laius, ${ }^{20}$ Gisbert Selke ${ }^{10},{ }^{21}$ Irene Langner, ${ }^{21}$ András Harsanyi, ${ }^{22}$ András Inotai, ${ }^{23}$ \\ Arianit Jakupi, ${ }^{24}$ Svens Henkuzens, ${ }^{25}$ Kristina Garuolienè, ${ }^{26}$ Jolanta Gulbinovič, ${ }^{26}$ \\ Patricia Vella Bonanno, ${ }^{1,27}$ Jakub Rutkowski, ${ }^{5}$ Skule Ingeberg, ${ }^{28}$ Øyvind Melien, ${ }^{28}$ \\ Ileana Mardare $\mathbb{D}^{\mathrm{D}},{ }^{29}$ Jurij Fürst, $^{30}$ Sean MacBride-Stewart ${ }^{\mathrm{D}},{ }^{31}$ Carol Holmes, $^{32}$ \\ Caridad Pontes $\mathbb{D}^{33,34}$ Corinne Zara ${ }^{1},{ }^{33}$ Marta Turu Pedrola $\mathbb{D}^{33}{ }^{33}$ Mikael Hoffmann, ${ }^{35}$ \\ Vasileios Kourafalos, ${ }^{36}$ Alice Pisana, ${ }^{37}$ Rita Banzi, ${ }^{8}$ Stephen Campbell, ${ }^{38,39}$ \\ and Bjorn Wettermark (iD ${ }^{40}$
}

\footnotetext{
${ }^{1}$ Strathclyde Institute of Pharmacy and Biomedical Sciences, University of Strathclyde, Glasgow G4 ORE, UK

${ }^{2}$ Division of Public Health Pharmacy and Management, School of Pharmacy, Sefako Makgatho Health Sciences University, Pretoria, South Africa

${ }^{3}$ School of Pharmaceutical Sciences, Universiti Sains Malaysia, Penang, Malaysia

${ }^{4}$ Chair of Epidemiology and Preventive Medicine, Medical College, Jagiellonian University, Krakow, Poland

${ }^{5}$ HTA Consulting, Starowiślna Str. 17/3, 31-038 Krakow, Poland

${ }^{6}$ Public Health Scotland, Gyle Square, 1 South Gyle Crescent, Edinburgh, UK

${ }^{7}$ Department of Pharmacology, College of Pharmacy, Hawler Medical University, Erbil, Iraq

${ }^{8}$ Istituto di Ricerche Farmacologiche 'Mario Negri' IRCCS, Milan, Italy

${ }^{9}$ Department of Global Health Economics and Policy, University of Kragujevac, Kragujevac, Serbia

${ }^{10}$ Institute of Comparative Economic Studies, Faculty of Economics, Hosei University Tokyo, Tokyo, Japan

${ }^{11}$ Department of Pharmacy Practice and Policy, Faculty of Health Sciences, University of Namibia, Windhoek, Namibia

${ }^{12}$ Department of Pharmacy, Faculty of Medicine, University of Medicine, Tirana, Albania

${ }^{13}$ Dachverband der Österreichischen Sozialversicherungen, Kundmanngasse 21, AT-1030 Vienna, Austria

${ }^{14}$ Faculty of Medicine, Department of Social Pharmacy, University of Banja Luka, Banja Luka, Bosnia and Herzegovina

${ }^{15}$ Faculty of Medicine, Department of Medicinal Chemistry, University of Banja Luka, Banja Luka, Bosnia and Herzegovina

${ }^{16}$ Agency for Medicinal Product and Medical Devices of Bosnia and Herzegovina, 78000 Banja Luka, Bosnia and Herzegovina

${ }^{17}$ Faculty of Pharmacy, Department of Social Pharmacy and Pharmacoeconomics, Medical University of Sofia, Sofia, Bulgaria

${ }^{18}$ State Institute for Drug Control, Prague, Czech Republic

${ }^{19}$ Department of Medical Biophysics, Faculty of Medicine in Hradec Králové, Charles University, Simkova 870, 50003 Hradec Králové, Czech Republic

${ }^{20}$ State Agency of Medicines, Nooruse 1, 50411 Tartu, Estonia

${ }^{21}$ Wissenschaftliches Institut der AOK (WIdO), Rosenthaler Straße 31, 10178 Berlin, Germany

${ }^{22}$ Department of Health Policy and Health Economics, Eotvos Lorand University, Budapest, Hungary

${ }^{23}$ Syreon Research Institute and Semmelweis University, Center of Health Technology Assessment, Budapest, Hungary

${ }^{24}$ Faculty of Pharmacy, UBT Higher Education Institute, Pristina, Kosovo

${ }^{25}$ Independent Consultant, Riga, Latvia

${ }^{26}$ Department of Pathology, Forensic Medicine and Pharmacology, Institute of Biomedical Sciences, Faculty of Medicine, Vilnius University, Vilnius, Lithuania

${ }^{27}$ Department of Health Services Management, University of Malta, Valletta, Malta
} 


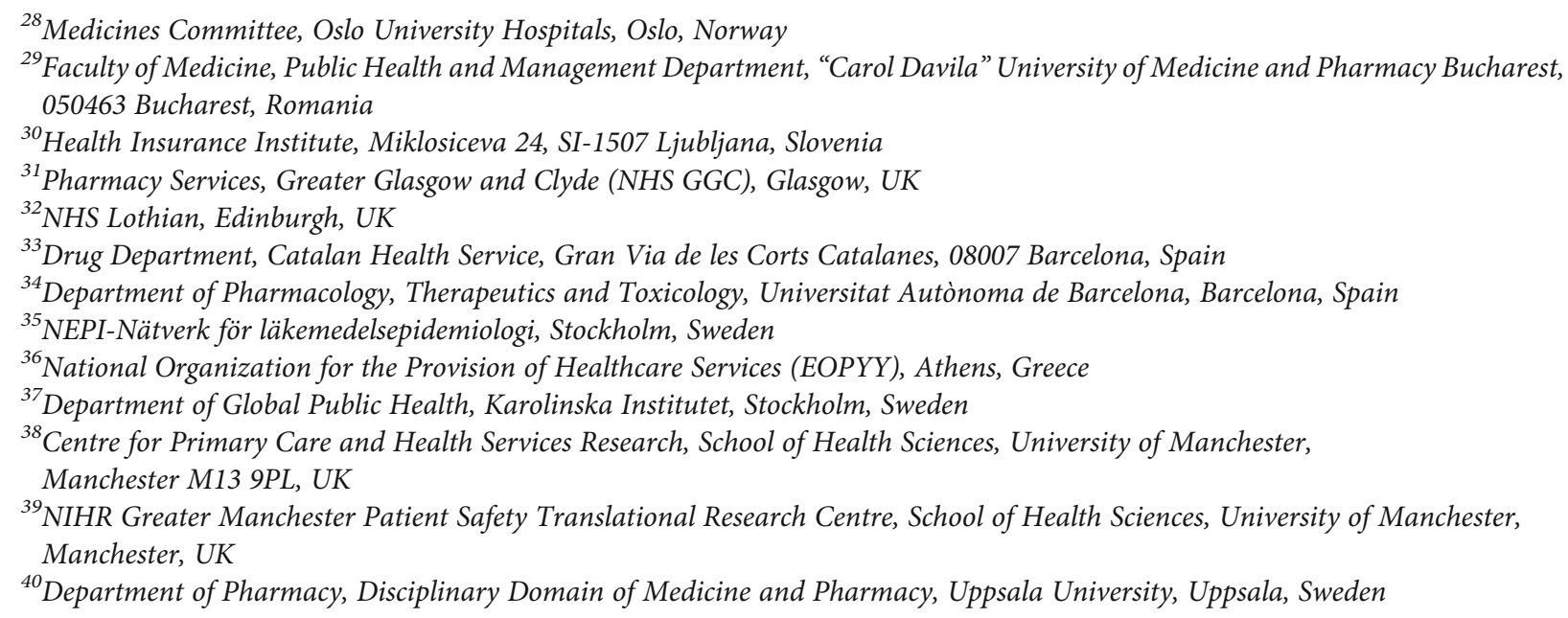

Correspondence should be addressed to Brian Godman; brian.godman@strath.ac.uk

Received 26 March 2021; Accepted 6 August 2021; Published 11 October 2021

Academic Editor: Kumud Kafle

Copyright (C) 2021 Brian Godman et al. This is an open access article distributed under the Creative Commons Attribution License, which permits unrestricted use, distribution, and reproduction in any medium, provided the original work is properly cited.

Background. Diabetes mellitus rates and associated costs continue to rise across Europe enhancing health authority focus on its management. The risk of complications is enhanced by poor glycaemic control, with long-acting insulin analogues developed to reduce hypoglycaemia and improve patient convenience. There are concerns though with their considerably higher costs, but moderated by reductions in complications and associated costs. Biosimilars can help further reduce costs. However, to date, price reductions for biosimilar insulin glargine appear limited. In addition, the originator company has switched promotional efforts to more concentrated patented formulations to reduce the impact of biosimilars. There are also concerns with different devices between the manufacturers. As a result, there is a need to assess current utilisation rates for insulins, especially long-acting insulin analogues and biosimilars, and the rationale for patterns seen, among multiple European countries to provide future direction. Methodology. Health authority databases are examined to assess utilisation and expenditure patterns for insulins, including biosimilar insulin glargine. Explanations for patterns seen were provided by senior-level personnel. Results. Typically increasing use of long-acting insulin analogues across Europe including both Western and Central and Eastern European countries reflects perceived patient benefits despite higher prices. However, activities by the originator company to switch patients to more concentrated insulin glargine coupled with lowering prices towards biosimilars have limited biosimilar uptake, with biosimilars not currently launched in a minority of European countries. A number of activities were identified to address this. Enhancing the attractiveness of the biosimilar insulin market is essential to encourage other biosimilar manufacturers to enter the market as more long-acting insulin analogues lose their patents to benefit all key stakeholder groups. Conclusions. There are concerns with the availability and use of insulin glargine biosimilars among European countries despite lower costs. This can be addressed.

\section{Introduction}

Global expenditure on medicines is envisaged to reach US $\$ 1.5$ trillion by 2023 enhanced by growing prevalence rates for noncommunicable diseases (NCDs) [1,2]. This is a concern among European countries given their desire to retain universal healthcare as a core principle as well as limit out-of-pocket expenditures especially among citizens with low income [3-6]. Currently across Europe, approximately one-fifth of health spending is paid for out of pocket, with a higher proportion among those with low income potentially leading to catastrophic consequences [4].

One NCD of increasing priority is diabetes mellitus, where prevalence rates grew to 463 million people worldwide in 2019 [7, 8]. In Europe, approximately 59 million people are currently estimated to have diabetes, with this number predicted to rise to 68 million by 2045 [9]. Whilst the majority of these patients will have type 2 diabetes (T2DM), up to $30 \%$ or more of patients with diabetes require insulin to help control HbA1c levels [10-13].

As a result of growing prevalence rates, the global economic burden of diabetes is envisaged to be as high as $2.2 \%$ of Gross Domestic Product (GDP) by 2030 [14], supported by GDP growth rates worldwide across many countries including developing countries $[15,16]$. The economic impact of diabetes is enhanced by the cost of the complications including complications arising from hypoglycaemia $[9,13,17,18]$. This is important with estimated rates of hypoglycaemia up to 3.5-3.6 events/month among patients with type 1 diabetes (T1DM) and 2.2-3.7 among those with type 2 diabetes (T2DM) [19-23], with some authors finding that rates of hypoglycaemia may be similar for T2DM 
patients taking insulins for $>5$ years [13]. In addition, the serious consequences of hypoglycaemia may turn out to be greater in T2DM patients, particularly regarding the effects on the cardiovascular system [13]. Overall, diabetes is among the leading causes of nontraumatic lower extremity amputation and blindness worldwide, with patients with diabetes also at greater risk of cardiovascular disease [7, 24-26]. In view of this, it is important that patients with diabetes should be carefully managed, which includes reducing the risk of hypoglycaemia [13].

Long-acting insulin analogues were specifically developed to lower the risk of hypoglycaemia in patients with diabetes requiring insulin, especially nocturnal hypoglycaemia, as well as improve patient convenience through reducing the number of injections thereby enhancing adherence rates, which is a continuing concern with insulin [7, 9, 27-30]. There is still controversy though regarding the level of benefit seen with long-acting insulin analogues versus NPH and other insulins [31-33]. However, a recent systematic review and network meta-analysis suggests that long-acting insulin analogues were superior to intermediate-acting insulins in key areas including major, serious, and nocturnal hypoglycaemia [34]. Having said this, the perceived patient benefits of long-acting insulin analogues are potentially reflected by their usage now typically exceeding that of human insulins in upper-middle and high-income countries as well as growing in lower middle-income countries including Bangladesh [35-37]. In addition, global expenditure on insulin glargine was already US $\$ 3.88$ billion in 2018 out of a total market of US\$24million and envisaged to potentially reach as high as US $\$ 9.26$ billion by 2025 helped by growing sales of Toujeo ${ }^{\circledR}$ $300 \mathrm{IU} / \mathrm{ml}[38,39]$. Expenditure on insulin detemir was US\$2.7 billion in 2015, growing at 7.5\% per year [40], with sales of insulin degludec also growing with studies demonstrating their improved effectiveness and cost-effectiveness versus other long-acting insulin analogues [41-45].

However, there are concerns with the high costs of longacting insulin analogues compared to Neutral Protamine Hagedorn (NPH) and other insulins [31, 35, 46]. This is not universal though with published studies showing that the higher acquisition costs of long-acting insulin analogues can be fully or partially offset by savings from averted costs of hypoglycaemia and other diabetes-associated complications [47-51].

Biosimilars are a potential way forward to reduce the cost of long-acting insulin analogues building on the appreciable price reductions seen with biosimilars to treat rheumatoid arthritis [52-56]. In addition, a number of published studies have now demonstrated similar effectiveness and safety between the originator and biosimilar long-acting insulin analogues [57-61]. However, potential savings from biosimilar insulin glargine can be limited in practice, potentially accentuated by the dominance of three companies currently controlling $96 \%$ of the global insulin market by volume and $99 \%$ by value discouraging competition $[36,46]$. We have seen this in the United Kingdom with limited price differences with Semglee ${ }^{\circledR}$ (biosimilar insulin glargine $100 \mathrm{IU} / \mathrm{ml}$ ) currently priced only $20 \%$ below the originator price and only $15 \%$ below the price of Abasaglar ${ }^{\circledR}$ (another biosimilar insulin glargine) [62]. Alongside this, there are concerns with increased rates of hypoglycaemia if patients are switched between different formulations of insulin glargine $100 \mathrm{IU} / \mathrm{ml}$ with different devices without full patient education [63-65]. These limited price differences were also seen in a recent study by Ewen et al. where median biosimilar prices for insulin glargine across lower- and middle-income (LMIC) countries ranged from $2 \%$ to $25 \%$ below originator prices, and sometimes biosimilar prices were higher in private pharmacies [35]. However, this was not the case in a recent study in Bangladesh with appreciable price reductions for biosimilar insulin glargine enhanced by competition between manufacturers [37]. WHO prequalification should also enhance competition leading to lower prices for biosimilar longacting insulin analogues [66]. This is welcomed since limited price reductions for the biosimilar analogues can easily be matched by the originator company to protect its market given envisaged low cost of goods apart from insulin detemir $[46,67]$. As a result, the attractiveness of the European longacting insulin analogue market for biosimilar manufacturers could be potentially reduced, and thereby, possible competition leading to lower prices.

Concerns regarding the different devices between the originator and biosimilars may well have resulted in the low use of insulin glargine biosimilars (9\%) among diabetologists in the UK in 2017 further limiting the attractiveness of the long-acting insulin biosimilar market [68]. However, this is not universal with some commissioning groups in England achieving utilisation rates of $53.3 \%$ for biosimilar insulin glargine in December 2018 versus total insulin glargine [69].

Other activities to reduce the attractiveness of the longacting insulin analogue market for biosimilar manufacturers include the originator company launching more concentrated patented formulations to enhance patient convenience and potentially further reduce rates of hypoglycaemia, i.e., a $300 \mathrm{IU} / \mathrm{ml}$ formulation of insulin glargine (Gla-300) [41, 70-75]. Having said this, other researchers have found no difference in effectiveness between the different strengths of insulin glargine and concerns with possible underdosing with the $300 \mathrm{IU} / \mathrm{ml}$ formulation [76]. These "evergreening" activities by the originator company to preserve its market share in the face of potential competition are similar to the launch of different devices for the treatment of asthma to try and improve adherence rates and protect sales as well as the development of longer-acting oral formulations and intramuscular formulations of atypical antipsychotics to improve compliance and reduce recurrences [77-80]. Such company activities are also seen in other disease areas. These include the launch of esomeprazole versus omeprazole, escitalopram versus citalopram, and pregabalin versus gabapentin [81-85]. We are aware of prescribing restrictions for Gla300 in some of the European countries [86]; however, this is not universal, and sales are growing especially with publications suggesting improved cost-effectiveness versus $100 \mathrm{IU} / \mathrm{ml}$ formulations [41].

Consequently, in view of the current controversies and issues surrounding the use of long-acting insulin analogues as well as the biosimilars, we believe that there is a need to assess current utilisation and expenditure patterns for the 
long-acting insulin analogues including biosimilars across Europe and the rationale for any patterns seen. The findings can be used by health authorities across Europe to enhance the use of biosimilar long-acting insulin analogues where pertinent to limit the budget impact of increasing the number of patients with diabetes across Europe including those requiring insulins. This will be important to preserve universal access especially post-COVID-19 with its resultant impact on available resources coupled with increases in patients with NCDs and their complications as a result of lockdown and other measures $[87,88]$.

\section{Materials and Methods}

We included a range of European countries incorporating both Western as well as Central and Eastern European (CEE) countries covering a range of geographies, epidemiology, and economic power in terms of GDP per population. This is similar to other studies conducted across Europe [89-91]. We particularly wanted to include CEE countries since there has been appreciably lower use of biologicals in these countries versus Western European countries due to issues of cost and affordability [92-96].

We typically used reimbursed data from heath authority and health insurance company databases from 2014 or later until 2020 when assessing utilisation and pricing patterns for the different insulin preparations. These were supplied by coauthors in each country since the content of these databases are typically not publicly available. This is different to studies by Beran et al. and Ewen and colleagues who use a wide variety of sources when computing cost data [35, 46, 97]. This is because the perspective of this paper is a health authority one; consequently, we concentrated on their databases. These databases are also seen as robust, and they are regularly audited $[89,98,99]$. Consequently, health authority data is seen as a reliable source for comparing and contrasting utilisation and expenditure patterns across countries [98]. We principally centred on insulin glargine as this is the only biosimilar insulin currently available across Europe at the time of the study.

Utilisation data was broken down into Defined Daily Doses (DDDs). This is because DDDs are seen as a key standard for comparing utilisation patterns across countries especially if there are different pack sizes and strengths between countries [100-102]. We acknowledge that some published studies have suggested that DDDs may understate the amount of insulin that patients prescribed $300 \mathrm{IU} / \mathrm{ml}$ insulin glargine receive versus those prescribed $100 \mathrm{IU} / \mathrm{ml}$ formulation; however, others have not seen this $[74,103]$. We have used this approach before in multiple publications when assessing utilisation and expenditure patterns across disease areas and countries [89-91, 104-107].

Expenditure data was principally reimbursed data since, as mentioned, the perspective of this paper is a health authority one. In a minority of situations, we also used total expenditure where it proved difficult to break expenditures down into the individual components. This again is in line with previous publications [89-91, 104-108]. Expenditure data remained where relevant in the local currency as we were principally interested in percentage differences in costs over time between the originator and biosimilars, as well as price reductions over time, rather than absolute levels and without any influence from currency fluctuations.

Utilisation and expenditure data on insulin glargine was further broken down into the different formulations, e.g., different $100 \mathrm{IU} / \mathrm{ml}$ formulations, as well as for the $300 \mathrm{IU} / \mathrm{ml}$ formulation (Gla-300) since, as mentioned, we were aware that the parent company had been switching its promotional activities towards the patented $300 \mathrm{IU} / \mathrm{ml}$ formulation in recent years to protect its market and help deter biosimilar manufacturers.

We combined the information from over 20 European countries and regions to provide the following datasets for comparisons:

(i) Utilisation of long-acting insulin analogues as a percentage of total insulin utilisation based on DDDs

(ii) Expenditure on long-acting insulin analogues as a percentage of total insulin expenditure based on local currencies

(iii) Utilisation of biosimilar insulin glargine $(100 \mathrm{IU} / \mathrm{ml})$ as a percentage of total insulin glargine $(100 \mathrm{IU} / \mathrm{ml})$ again based on DDDs

(iv) Utilisation of insulin glargine $300 \mathrm{IU} / \mathrm{ml}$ as a percentage of total insulin glargine again based on DDDs

(v) Cost/DDD for both originator and biosimilar insulin glargine $(100 \mathrm{IU} / \mathrm{ml})$ over time with the data subsequently used to track price changes over time

The information on utilisation and expenditure patterns was supplemented by feedback from the coauthors regarding the patterns seen in their countries to provide future guidance. The senior-level coauthors also contributed to discussions regarding potential next steps to enhance future savings from increased utilisation of biosimilars based on their considerable experience in this area. We have adopted similar approaches before to provide future guidance in this and other areas [55, 89, 104, 109-113].

We did not seek ethical approval as we were not dealing with patients. This is in line with national legislation and institutional guidelines as well as multiple previous papers conducted by the coauthors in other disease areas and situations [89, 104, 105, 114-116].

\section{Results}

3.1. Utilisation for the Different Insulin Preparations Over Time. There has been growing utilisation for long-acting insulin analogues over time among both Western and CEE countries, with no obvious difference in the rates of utilisation and increase between Western and CEE countries (Figure 1). This reflects the growing recognition of the role and value of long-acting insulin analogues in the management of patients with diabetes mellitus across Europe coupled with their increasing promotion. 


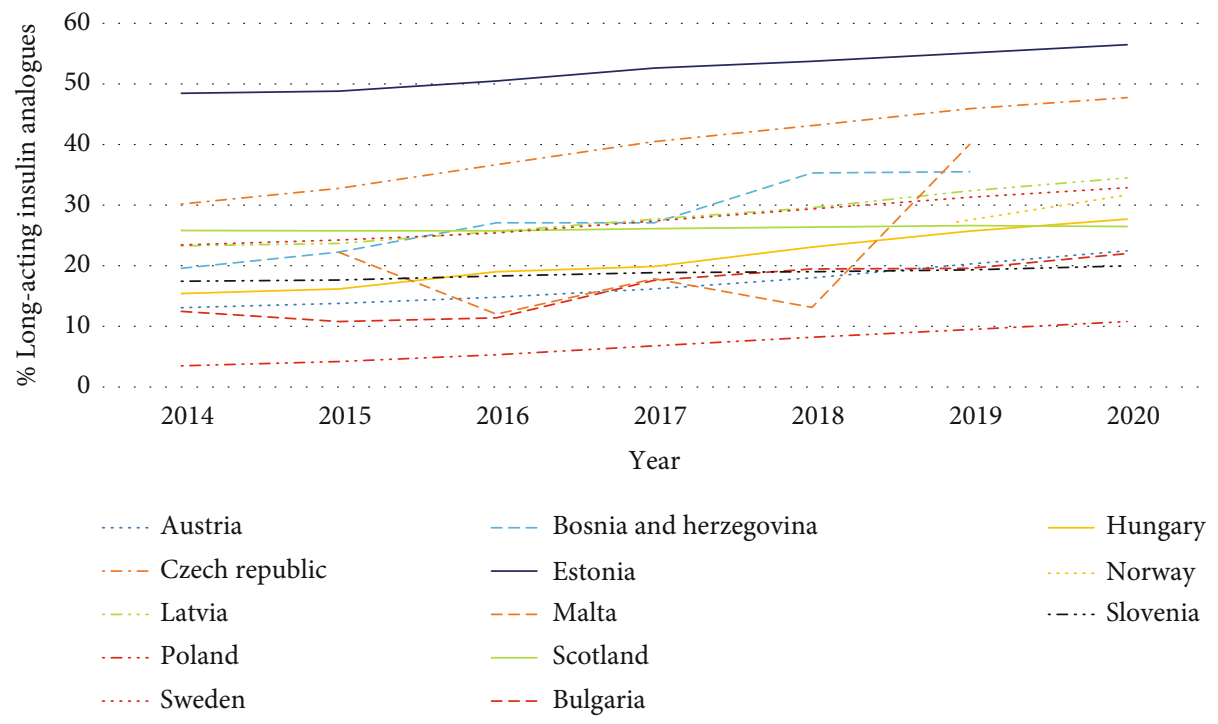

FIGURE 1: Utilisation of long-acting insulin analogues as a percentage of total insulins over time across Europe (DDD based).

The greatest utilisation of long-acting insulin analogues in recent years was seen in Estonia (56.5\% of total insulins), Czech Republic (47.8\%), and Malta (40.0\%). There was also considerable prescribing of long-acting insulin analogues in Catalonia in recent years reaching $55.2 \%$ of total insulins in 2020 (not shown in Figure 1). However, the variable use of long-acting insulin analogues in Malta reflects procurement practices for that year; consequently, rates can be flexible between the years with implications for accuracy for any one year.

The least change in the prescribing patterns for longacting insulin analogues was seen in Scotland (2.7\% increase over time), with the greatest change seen in Poland $(210.6 \%$ increase over time), but from a low base. In Poland, this may reflect a more cautious attitude towards long-acting insulin analogues coupled with issues of affordability. There was also a more cautious approach to the prescribing of long-acting insulin analogues in Slovenia, with similar prescribing rates over time $(10.7 \%$ increase between 2014 and 2019). This may again reflect issues of value and affordability; however, more research is needed before we can say anything with certainty.

The stable utilisation of long-acting insulin analogues in Scotland in recent years (Figure 1) may well reflect adherence to the advice from NHS Scotland that patients in Scotland should ideally be started on human intermediate acting insulins, with long-acting insulin analogues only considered based on an assessment of a patient's hypoglycaemic risk. Adherence to agreed guidance is enhanced by regular monitoring of physicians' prescribing of longacting insulin analogues versus other insulin preparations in Scotland [117]. We have seen monitoring of advice increase adherence rates to prescribed guidance in other disease areas in Scotland $[83,84,118]$.

\subsection{Expenditure for the Different Insulin Preparations Over} Time. The increasing use of long-acting insulin analogues as a percentage of total insulins (Figure 1) was also reflected in similar changes in their expenditure compared with total expenditure on insulins (Figure 2).

Variations ranged from a slight fall in Romania and Slovenia over time with the cost/DDD for originator insulin glargine $100 \mathrm{IU} / \mathrm{ml}$ falling by $20.3 \%$ over time in Slovenia (Table 1) to a limited change in overall expenditure in Malta with the cost/DDD falling by $61.3 \%$ during the study period (Table 1). This compares with an appreciable increase in expenditure of long-acting insulin analogues in Kosovo over time but from a low base.

Increasing expenditure on long-acting insulins in Kosovo in recent years again reflects perceptions of improved patient convenience and outcomes versus standard insulins such as $\mathrm{NPH}$ insulins. There is a similar situation in Hungary with expenditure on long-acting insulins reaching $53.7 \%$ of total expenditure in recent years, similar to high expenditure rates in Estonia (63\% in 2020), the Czech Republic (62.4\%), and Latvia (45.5\%). There was also appreciable expenditure on long-acting insulin analogues in Catalonia currently at $63.2 \%$ of total insulin expenditure (not shown).

The relatively high expenditure on long-acting insulins in Romania in recent years again reflects successful marketing by the originator companies with insulin glargine being one of the top selling medicines in Romania in recent years joined recently by insulin detemir.

3.3. Utilisation of Insulin Glargine including Biosimilar $100 \mathrm{IU} / \mathrm{ml}$ and $300 \mathrm{IU} / \mathrm{ml}$ (Gla-300). There has also been considerable variation in the use of biosimilar insulin glargine $(100 \mathrm{IU} / \mathrm{ml})$ versus total insulin glargine across Europe (Figure 3). This reflects a number of differences between countries in terms of switching of prescribing of insulin glargine from $100 \mathrm{IU} / \mathrm{ml}$ to patented $300 \mathrm{IU} / \mathrm{ml}$ (Gla-300) as well as activities of the originator company to lower its price to make the market less attractive for biosimilars.

Currently, no biosimilar insulin glargine is marketed in Albania, Austria, or Latvia. This may reflect increasing utilisation of Gla-300 in recent years rising to $45.3 \%, 47.7 \%$, and 


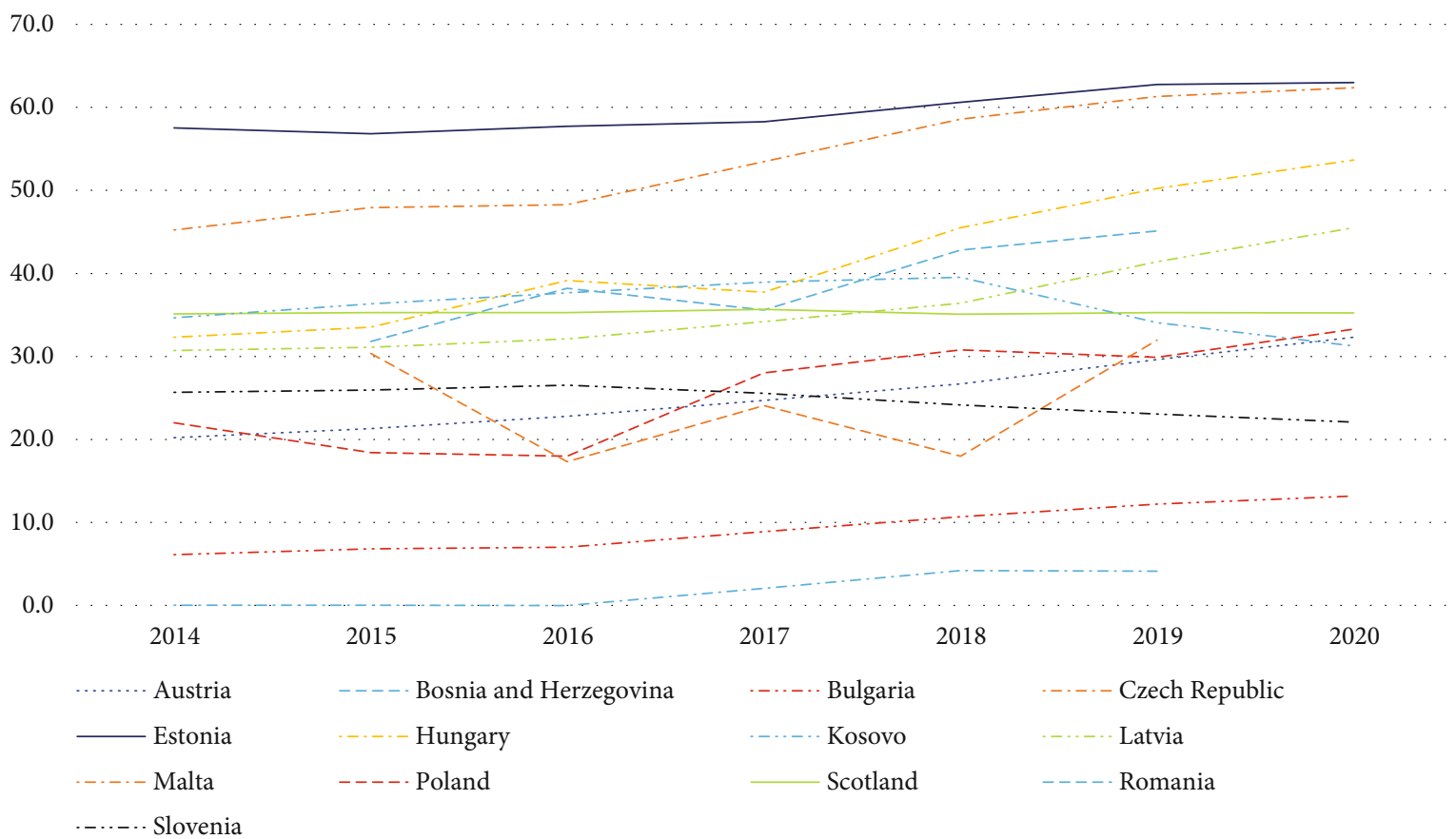

FIGURE 2: Expenditure on long-acting insulin analogues as a percentage of total insulin expenditure over time among European countries.

$51.4 \%$, respectively, of total insulin glargine in these countries as a result of commercial and other activities (Figure 4). This coupled with reduced prescribing generally of insulin glargine (Latvia), and price reductions of the originator over time (Albania and Latvia) (Table 1) appear to have made the $100 \mathrm{IU} / \mathrm{ml}$ biosimilar market unattractive in these countries. This is despite insulin glargine being the predominant longacting insulin analogue prescribed in Albania in recent years, rising to $81.1 \%$ of total long-acting insulin analogues (DDD basis) prescribed.

There is also currently no biosimilar insulin glargine imported into Kosovo due to a number of issues including concerns with their effectiveness and safety versus the originator, and currently there is no biosimilar insulin glargine prescribed in Malta despite very limited use of Gla-300 (Figure 4). This probably reflects the considerable price reduction by the originator company making this market unattractive to biosimilar manufacturers (61.3\%, Table 1). Similarly, whilst insulin glargine biosimilar has recently been reimbursed in Romania (Abasaglar ${ }^{\circledR} 100$ ), its uptake to date has been very limited (not shown) due to ongoing pricing and reimbursement policies coupled with limited physician incentives to preferentially prescribe biosimilars alongside no copayment issues for patients.

There was also very limited utilisation of insulin glargine biosimilars in Estonia, contrasting with their growing utilisation in Lithuania as another key member of the Baltic States. This again probably reflects the originator company switching promotional activities to patented Gla-300 in Estonia to reduce biosimilar competition, with utilisation of Gla-300 growing to $55.4 \%$ of total insulin glargine in 2020 (Figure 4). In addition, the originator company dropping its price by $24.9 \%$ over time (Table 1 ) resulting in limited price differences in recent years between the originator and biosimilars $(2.1 \%-7.1 \%)$.

Low and constant utilisation of biosimilar insulin glargine in Bulgaria again reflects continued marketing activities by the originator company coupled with currently a lack of physician incentives to preferentially prescribe biosimilars alongside limited price difference in practice between the originator and the biosimilar (Table 1), with both reducing their prices over time.

Low utilisation of insulin glargine biosimilars in Norway also potentially reflects limited price differences between the originator and biosimilar in recent years (Table 1) coupled with growing utilisation of Gla-300 (Figure 4). This contrasts with Sweden which has the highest biosimilar use among the studied European countries (Figure 3) despite growing use of Gla-300 (Figure 4). This is probably due to a tradition of prescribing of multiple source medicines with compulsory generic substitution in Sweden coupled with ongoing initiatives to enhance the quality and efficiency of prescribing including enhancing the prescribing of biosimilars $[55,106$, $119,120]$. Ongoing initiatives also include devolving budgets locally to enhance the focus of ambulatory care physicians on prescribing efficiency.

The situation in Lithuania contrasts with the other Baltic countries as there has been growing utilisation of biosimilar insulin glargine as a percentage of all insulin glargine $100 \mathrm{IU} / \mathrm{ml}$ in recent years, reaching $26.5 \%$ of total insulin glargine $100 \mathrm{IU} / \mathrm{ml}$ in 2020 (Figure 3). This reflects the fact that all long-acting insulin analogues are in the same reference price group with patients covering the additional costs themselves for a more expensive medicine [121, 122]. Having said this, utilisation of the $100 \mathrm{IU} / \mathrm{ml}$ formulation has been moderated in recent years in Lithuania by increasing 
TABLE 1: Changes in differences between prices for the originator and biosimilar insulin glargine $100 \mathrm{IU} / \mathrm{ml}$ across Europe in recent years (based on local costs/DDD).

(a)

\begin{tabular}{|c|c|c|c|c|c|}
\hline & Albania & Austria & B \& H & Bulgaria & Catalonia (Spain) \\
\hline \multicolumn{6}{|c|}{$\%$ difference originator vs. biosimilar price } \\
\hline Launch of the biosimilar & Not applicable & Not applicable & No difference & $4.7 \%$ & $30.0 \%$ \\
\hline Latest difference & Not applicable & Not applicable & $7.9 \%$ & $5.7 \%$ & Similar \\
\hline \multicolumn{6}{|c|}{$\%$ price change over time (from $2014 / 2015$ to 2020 ) } \\
\hline Originator & $-32.0 \%$ & No change & $-11.3 \%$ & $-10.8 \%$ & $-23.1 \%$ \\
\hline Biosimilar & Not applicable & Not applicable & $-17.1 \%$ & $-11.7 \%$ & No change \\
\hline
\end{tabular}

(b)

\begin{tabular}{|c|c|c|c|c|c|c|}
\hline & Czech Republic & Estonia & Hungary & Italy & Latvia & Lithuania \\
\hline \multicolumn{7}{|c|}{$\%$ difference originator vs. biosimilar price } \\
\hline Launch of the biosimilar & $17.1 \%$ & $16.4 \%$ & $28.2 \%$ & Not recorded & Not applicable & $12.3 \%$ \\
\hline Latest difference & Similar & $7.1 \%$ & $1.6 \%$ & $31.6 \%$ & Not applicable & Similar \\
\hline \multicolumn{7}{|c|}{$\%$ price change over time (from $2014 / 2015$ to 2020 ) } \\
\hline Originator & $-25.5 \%$ & $-24.9 \%$ & $-21.2 \%$ & $52.3 \%$ & $-14.4 \%$ & $-21.1 \%$ \\
\hline Biosimilar & $-7.7 \%$ & Stable & $1.2 \%$ & Not recorded & Not applicable & $-6.8 \%$ \\
\hline
\end{tabular}

(c)

\begin{tabular}{|c|c|c|c|c|c|c|}
\hline & Malta & Norway & Poland & Scotland & Slovenia & Sweden \\
\hline \multicolumn{7}{|c|}{ \% difference originator vs. biosimilar price } \\
\hline Launch of the biosimilar & Not applicable & $12.1 \%$ & $24.7 \%$ & $18.1 \%$ & $22.9 \%$ & $13.6 \%$ \\
\hline Latest difference & Not applicable & $5.9 \%$ & $0.2 \%$ & $7.5 \%$ & $9.9 \%$ & $0.6 \%$ \\
\hline \multicolumn{7}{|c|}{$\%$ price change over time (from $2014 / 2015$ to 2020 ) } \\
\hline Originator & $-61.3 \%$ & $-3.6 \%$ & $-31.1 \%$ & $-9.0 \%$ & $-20.3 \%$ & $-12.7 \%$ \\
\hline Biosimilar & Not applicable & $2.1 \%$ & $-6.5 \%$ & No change & No change & $-1.4 \%$ \\
\hline
\end{tabular}

utilisation of Gla-300, rising to $39.0 \%$ of all insulin glargine in early 2020 (Figure 4) coupled with price reductions by the originator (21.1\% between 2015 and 2020) to limit any copayment differences.

There has also been growing utilisation of insulin glargine biosimilars in Bosnia and Herzegovina ( $B \& \mathrm{H}$ ), but from a low base with the state agency recently encouraging physicians to prescribe biosimilars for new patients where possible, with physicians generally following national guidelines in B \& $\mathrm{H}[108,123]$. Greater growth though is hampered by high utilisation of Gla-300, reaching $52.1 \%$ of all insulin glargine use in 2019 (Figure 4), and the originator dropping its price to reduce any resultant price differential (Table 1).

The growth in the utilisation of the biosimilar in Hungary is also welcomed as this was not the case with biosimilars for infliximab and rituximab $[124,125]$. However, there are now ongoing reforms in Hungary to encourage physicians to start patients on the least expensive biosimilar as well as the reference pricing system with patients required to fund the difference in prices between the originator and any biosimilar themselves [126]. Having said this, utilisation of biosimilar insulin glargine in Hungary is again adversely affected by the originator dropping its price over time (Table 1) coupled with increasing use of Gla-300 reaching $58 \%$ of total insulin glargine in recent years (Figure 4).

The growth in the prescribing of biosimilar $100 \mathrm{IU} / \mathrm{ml}$ insulin glargine in Italy in recent years (Figure 3) probably reflects ongoing regional and national demand-side measures to enhance the prescribing of biosimilars given some of the price differences seen including for biosimilar insulin glargine (Table 1) and the need to conserve resources [127, 128]. However, greater utilisation of biosimilar insulin glargine may again be hampered by growing utilisation of Gla-300 in Italy in recent years (Figure 4).

We are also seeing growing utilisation of biosimilar insulin glargine in Scotland. However, growth is limited by concerns with switching between the originator and biosimilar $100 \mathrm{IU} / \mathrm{ml}$ insulin glargine, with physicians requesting to prescribe by brand name $[64,65]$. This works in the UK with community pharmacists not allowed to substitute an originator with a generic without physician approval [80, 129]. Having said this, there are traditionally very high rates of INN prescribing in Scotland $[83,84,118]$. There is currently 


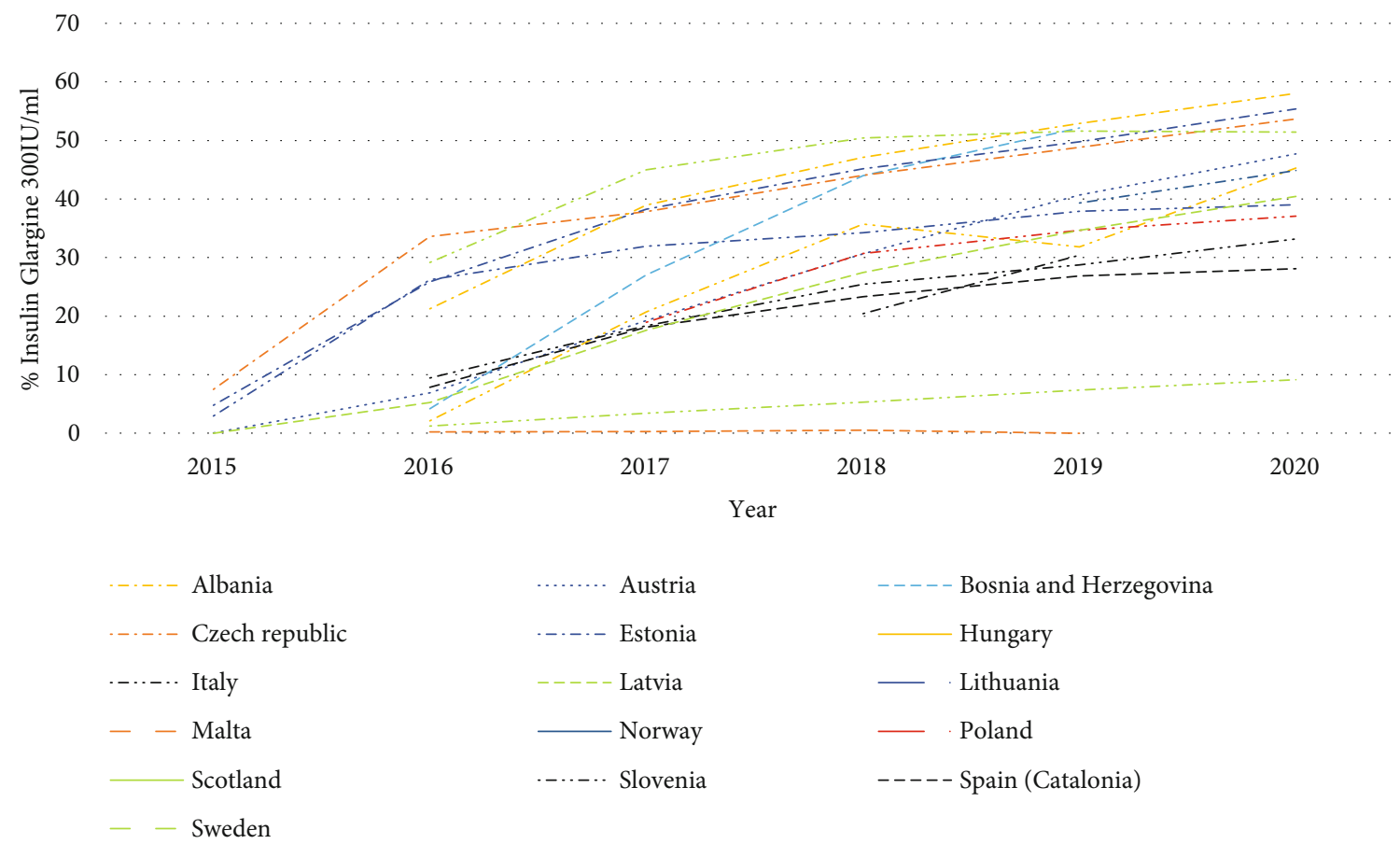

FIGURE 3: Utilisation of insulin glargine biosimilar $(100 \mathrm{IU} / \mathrm{ml})$ as a $\%$ of total insulin glargine $100 \mathrm{IU} / \mathrm{ml}$ (DDD based) over time across Europe.

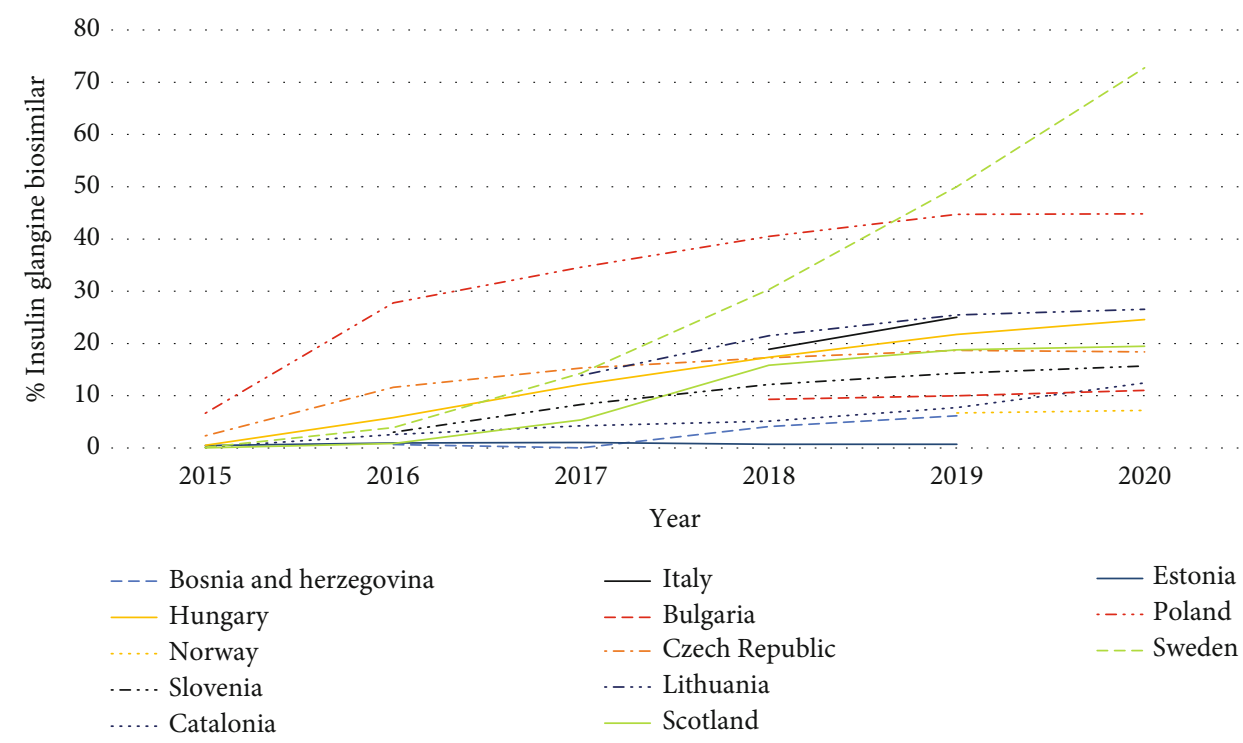

FIGURE 4: Utilisation of insulin glargine $300 \mathrm{IU} / \mathrm{ml}$ (Gla-300) as a \% of total insulin glargine (DDD based) across Europe over time

low use of Gla-300 in Scotland as a result of ongoing prescribing guidance to limit its use enhanced by concerns that patients may inadvertently over dose [86].

The appreciably higher utilisation of biosimilar insulin glargine in Poland in recent years compared with a number of other CEE countries (Figure 3) may well be facilitated by a flat reimbursement rate with patients paying the price difference for a more expensive originator [126, 130]. Alongside this, the Ministry of Health and the National Health Insurance Fund in Poland are both looking to encourage the use of biosimilars to save resources especially as Poland is a leading producer of biosimilars in Europe [130, 131]. However, their prescribing is also hampered by growing utilisation of Gla-300 reaching $37.1 \%$ of total insulin glargine by early 2020 (Figure 4).

Prices are also now similar between the biosimilar insulin glargine and the originator in the Czech Republic potentially impacting on its use following a fall in originator prices $(25.5 \%)$ and also biosimilar prices (7.7\%) (Table 1). As a result, there is limited use of biosimilars despite growing 
Educational initiatives

(i) Instigate programmes that educate patients where pertinent regarding similar effectiveness and safety between the originator and biosimilar insulin glargine. This includes actively disseminating the findings from previous and current studies including studies with real-world data

(ii) Instigate/help with additional research regarding the potential savings/cost-effectiveness from increasing use of biosimilar insulin glargine-building on current studies, with potential savings used to enhance either greater availability and use of long-acting insulin analogues in suitable patients with rising prevalence rates; alternatively, increase the number of professionals available to improve the care of patients with diabetes requiring insulin with the savings made

(iii) Alongside this, work with patients to ensure they are familiar with the different pens/devices where this exists in cases where switching between unfamiliar devices may cause confusion-the objective being to minimise any potential for hypoglycaemia

(iv) Concurrently, work with patient organisations to facilitate greater use of biosimilar insulin glargine especially where resources/copayments are an issue and help with patient education to enhance optimal use of available devices where pertinent [132]

(v) Increased competition with greater availability of biosimilars should help to further lower prices benefitting all key stakeholder groups

Other suggested activities

(i) Encourage greater discounts from companies to enhance the use of biosimilar insulin glargine at lower costs-building on examples with oral generics $[122,133,134]$. This includes helping to cover the costs of any educational activities needed to enhance familiarity with different devices to minimise potential hypoglycaemia

(ii) Potential activities to encourage increased prescribing of biosimilars (and hence competition) could include the following:

(a) Introducing/progress annual procurement practices-with preference given to biosimilar companies

(b) Consider potentially delisting originator insulin glargine $100 \mathrm{IU} / \mathrm{ml}$ from reimbursement and formulary lists and/or only authorising reimbursement for biosimilars-building on successes in other disease areas and situations $[118,135]$

(c) Introduce target prescribing goals for biosimilars for both new and existing patients with diabetes requiring insulin for their management-and where necessary provide additional educational support (with the help of patient organisations and other healthcare professionals)

(d) Introduce prescribing restrictions/guidance for still patented Gla-300 IU/ml to further enhance the market attractiveness for $100 \mathrm{IU} / \mathrm{ml}$ formulations-similar to the situation in Scotland [86]. This builds on the successful introduction of prescribing restrictions in other disease areas across Europe [91, 136-138]

(iii) Potentially form consortia surrounding the purchasing of biosimilar insulin glargine to encourage greater competition among manufacturers to reduce the current monopoly of insulin availability from the three leading pharmaceutical companies. This can build on current Pan-European consortia activities [139-141]

(iv) Look to increase European production of biosimilar insulin glargine building on current activities in countries such as Poland and Malaysia [130, 131, 142]. Lower prices for biosimilar insulin glargine should help lower- and middle-income countries struggling to fund long-acting insulin analogues due to issues of affordability [35, 143, 144]

Box 1: Potential activities among health authorities to enhance the prescribing and dispensing of biosimilar insulin glargine.

utilisation of long-acting insulin analogues in the Czech Republic reaching $47.8 \%$ of total insulins in 2020 (Figure 1). There are current restrictions regarding the prescribing of long-acting insulin analogues in the Czech Republic, with long-acting insulin analogues only reimbursed if current treatment regimens fail to achieve target $\mathrm{HbA} 1 \mathrm{c}$ levels below $60 \mathrm{mmol} / \mathrm{mol}$ or if patients prescribed human insulins repeatedly experience severe hypoglycaemia. Concomitant with this, treatment with long-acting insulin analogues should no longer be reimbursed unless there is a demonstrable improvement in the patient's HbAlc levels within three months of initiation, i.e., a reduction by at least $10 \%$, or significant reduction in the incidence of hypoglycaemia. However, there is currently variable follow-up of these restrictions in practice.

3.4. Potential Strategies to Enhance the Prescribing of Biosimilar Insulin Glargine. Box 1 contains a number of potential strategies to enhance the utilisation of biosimilar long-acting insulin analogues in Europe. This builds on currently variable utilisation of biosimilar insulin glargine across Europe. This is seen as essential to stimulate the market for the benefit of key stakeholders in the future.

\section{Discussion}

We believe this is the most comprehensive study to date to explore current utilisation and expenditure patterns for different insulin preparations, with a particular focus on insulin glargine and its biosimilars, across Europe. There has typically been increasing utilisation of long-acting insulin analogues across Europe despite their higher price (Figure 1), reflecting perceived patient benefits in terms or reduced hypoglycaemia and greater convenience. This increased use is seen in both Western European and CEE countries demonstrating that affordability is not an issue unlike a number of lower- and middle-income countries [35, 143, 145]. Similar patterns were seen when evaluating changes in expenditure on long-acting insulin analogues as a percentage of total expenditure on insulins (Figure 2).

However, there are concerns with limited or no use of biosimilar insulin glargine in a number of European countries despite a number of studies showing no difference in effectiveness and safety between the originator and biosimilars [57-60] (Section 3.3). This is due to a number of factors including promotional efforts by the originator company to change prescriptions to patented Gla-300 with limited 
demand-side initiatives from health authorities to discourage this with the exception of Scotland with its prescribing suggestions to limit the use of Gla-300 [86]. In addition, the company lowering the price of the originator often to near or similar to biosimilar prices (Table 1), which coupled with concerns with different devices between the different insulin glargine $100 \mathrm{IU} / \mathrm{ml}$ formulations in some markets, has further limited biosimilar use. Alongside this, the continued domination of the insulin market by three manufacturers discourages competition $[36,46]$.

These issues need to be addressed to enhance the attractiveness of the biosimilar long-acting insulin analogue market, especially with the potential for low cost of goods $[46,67]$. We have seen with biosimilars for managing patients with inflammatory diseases such as rheumatoid arthritis that increased competition can lead to low prices for biosimilars $[52,54,56,146]$, and this should be encouraged for long-acting insulin analogues in Europe. Failure to do so will limit the attractiveness of this market to other manufacturers of biosimilar insulin glargine as well as potential manufacturers of other long-acting insulin analogues as these compounds lose their patents. This will be to the detriment of key stakeholder groups especially given rising rates on diabetes across Europe [9] and growing resource issues postCOVID-19. Box 1 contains a number of activities that European health authorities can instigate to increase competition and subsequent prescribing of biosimilar long-acting insulin analogues, building on demand-side and other measures in other disease areas, and we will be monitoring these in the future.

We are aware of a number of limitations with this study. These include the fact that we did not include all European countries. However, we do not believe that increasing the number of European countries would have appreciably altered our findings. In addition, we only used health authority and health insurance company databases. This was deliberate for the reasons stated. Thirdly, we used DDDs for documenting and analysing utilisation data aware though of the potential problems with Gla-300. This was again deliberate for the reasons stated. Finally, we did not undertake an in-depth analysis of the rationale behind the trends seen in each country. However, feedback was based on the experience of senior-level coauthors in each country. Consequently, we believe our findings and suggestions are robust providing future direction.

\section{Conclusion}

In conclusion, we have seen growing use of long-acting insulin analogues across Europe reflecting their perceived benefits with improving compliance and reducing hypoglycaemia. However, there are concerns with limited or no use of biosimilars of long-acting insulin analogues in a number of European countries due to a number of factors. These include promotional efforts by the originator company and price reductions matching those of biosimilar manufacturers. These issues need to be addressed to enhance the utilisation of biosimilars in the future to the benefit of all key stakeholder groups.

\section{Data Availability}

The content of health authority and health insurance company databases is typically confidential. However, reasonable requests for information will be considered and actioned where possible. The coauthors from the various European countries have been responsible for the content and accuracy of the information they have provided.

\section{Disclosure}

The authors are totally responsible for the views expressed in this paper, and they do not necessarily represent the decisions, policy, or views of the World Health Organization.

\section{Conflicts of Interest}

The authors have no relevant conflicts of interest to declare. However, a number of the coauthors work for health authorities or are advisers to them.

\section{Acknowledgments}

The authors would like to thank Elita Poplavska with her help with explaining the potential rationale for the prescribing patterns in Latvia. This analysis was commissioned and paid for by the World Health Organization.

\section{References}

[1] IQVIA, The Global Use of Medicine in 2019 and Outlook to 2023 - Forecasts and Areas to Watch, 2019, https://www .iqvia.com/-/media/iqvia/pdfs/institute-reports/the-globaluse-of-medicine-in-2019-and-outlook-to-2023.pdf.

[2] M. Jakovljevic, M. Jakab, U. Gerdtham et al., "Comparative financing analysis and political economy of noncommunicable diseases," Journal of Medical Economics, vol. 22, no. 8, pp. 722-727, 2019.

[3] A. Odone and N. Azzopardi-Muscat, "Health and the effect of universal health coverage in Italy," The Lancet Public health., vol. 4, no. 12, pp. e597-e598, 2019.

[4] OECD, Health at a Glance: Europe 2020 State of Health in the EU Cyclehttps://www.oecd-ilibrary.org/docserver/82129230en.pdf? expires $=1612384979 \&$ id $=$ id \&accname $=$ guest\&checksum=E9AD44E432E325AC9EEBEB236EAE5851.

[5] European Commission, "Defining value in "value based healthcare"," Report of the expert panel on effective ways of investing in health (EXPH), 2019, https://ec.europa.eu/ health/sites/health/files/expert_panel/docs/024_definingvalue-vbhc_en.pdf.

[6] M. Jakovljevic, K. Matter-Walstra, T. Sugahara et al., "Costeffectiveness and resource allocation (CERA) 18 years of evolution: maturity of adulthood and promise beyond tomorrow," Cost effectiveness and resource allocation., vol. 18, no. $1,2020$.

[7] J. C. N. Chan, L. L. Lim, N. J. Wareham et al., “The Lancet Commission on diabetes: using data to transform diabetes care and patient lives," Lancet, vol. 396, no. 10267, pp. 2019-2082, 2021.

[8] J. Liu, Z.-H. Ren, H. Qiang et al., "Trends in the incidence of diabetes mellitus: results from the Global Burden of Disease 
Study 2017 and implications for diabetes mellitus prevention," BMC Public Health, vol. 20, no. 1, p. 1415, 2020.

[9] A. Ceriello, H. W. deValk, B. Guerci et al., "The burden of type 2 diabetes in Europe: current and future aspects of insulin treatment from patient and healthcare spending perspectives," Diabetes research and clinical practice, vol. 161, p. 108053, 2020.

[10] S. Basu, J. S. Yudkin, S. Kehlenbrink et al., "Estimation of global insulin use for type 2 diabetes, 2018-30: a microsimulation analysis," The lancet Diabetes \& endocrinology., vol. 7, no. 1, pp. 25-33, 2019.

[11] M. Sharma, I. Nazareth, and I. Petersen, "Trends in incidence, prevalence and prescribing in type 2 diabetes mellitus between 2000 and 2013 in primary care: a retrospective cohort study," BMJ Open, vol. 6, no. 1, article e010210, 2016.

[12] V. A P, L. Kamath, and S. Shankar, "Knowledge, attitude and practice of insulin use of diabetic patients in India," Pharmacology and Clinical Pharmacy Research., vol. 5, no. 1, pp. 23$32,2020$.

[13] S. R. Heller, M. Peyrot, S. K. Oates, and A. D. Taylor, "Hypoglycemia in patient with type 2 diabetes treated with insulin: it can happen," BMJ Open Diabetes Research \& Care, vol. 8, no. 1, p. e001194, 2020.

[14] C. Bommer, V. Sagalova, E. Heesemann et al., "Global economic burden of diabetes in adults: projections from 2015 to 2030," Diabetes Care, vol. 41, no. 5, pp. 963-970, 2018.

[15] M. Jakovljevic, Y. Timofeyev, C. L. Ranabhat et al., "Real GDP growth rates and healthcare spending - comparison between the G7 and the EM7 countries," Globalization and Health, vol. 16, no. 1, p. 64, 2020.

[16] M. Jakovljevic, T. Sugahara, Y. Timofeyev, and N. Rancic, "Predictors of (in)efficiencies of healthcare expenditure among the leading Asian economies - comparison of OECD and non-OECD nations," Risk management and healthcare policy., vol. Volume 13, pp. 2261-2280, 2020.

[17] S. A. Amiel, P. Aschner, B. Childs et al., "Hypoglycaemia, cardiovascular disease, and mortality in diabetes: epidemiology, pathogenesis, and management," The lancet Diabetes \& endocrinology, vol. 7, no. 5, pp. 385-396, 2019.

[18] S. Kalra, "Hypoglycaemia in diabetes," Journal Of Pakistan Medical Association, vol. 64, no. 9, pp. 1090-1093, 2014.

[19] M. F. Pathan, M. Fariduddin, K. Nazimuddin et al., "The incidence of hypoglycemia among insulin-treated patients with type 1 or type 2 diabetes: Bangladeshi cohort of international operations-hypoglycemia assessment tool study," Indian Journal of Endocrinology and Metabolism, vol. 22, no. 3, pp. 379-386, 2018.

[20] K. Khunti, S. Alsifri, R. Aronson et al., "Rates and predictors of hypoglycaemia in 27585 people from 24 countries with insulin-treated type 1 and type 2 diabetes: the global HAT study," Diabetes, obesity \& metabolism., vol. 18, no. 9, pp. 907-915, 2016.

[21] Z. Hussein, N. A. Kamaruddin, S. P. Chan et al., "Hypoglycemia awareness among insulin-treated patients with diabetes in Malaysia: a cohort subanalysis of the HAT study," Diabetes research and clinical practice., vol. 133, pp. 40-49, 2017.

[22] S. Abusnana, S. A. Beshyah, N. al-Mutawa et al., "Hypoglycaemia among insulin-treated patients with diabetes: evaluation of the United Arab Emirates cohort of the International Operations-Hypoglycaemia Assessment Tool study," Sultan
Qaboos University Medical Journal [SQUMJ], vol. 18, no. 4, pp. 447-e454, 2019.

[23] N. Munro and A. H. Barnett, "Incidence, worry and discussion about dosing irregularities and self-treated hypoglycaemia amongst HCPs and patients with type 2 diabetes: results from the UK cohort of the Global Attitudes of Patient and Physicians (GAPP2) survey," International journal of clinical practice., vol. 68, no. 6, pp. 692-699, 2014.

[24] M. L. Alva, A. Gray, B. Mihaylova, J. Leal, and R. R. Holman, "The impact of diabetes-related complications on healthcare costs: new results from the UKPDS (UKPDS 84)," Diabetic medicine., vol. 32, no. 4, pp. 459-466, 2015.

[25] A. Papazafiropoulou, N. Tentolouris, R. P. Soldatos et al., "Mortality in diabetic and nondiabetic patients after amputations performed from 1996 to 2005 in a tertiary hospital population: a 3-year follow-up study," Journal of Diabetes and its Complications, vol. 23, no. 1, pp. 7-11, 2009.

[26] M. Narres, T. Kvitkina, H. Claessen et al., "Incidence of lower extremity amputations in the diabetic compared with the non-diabetic population: a systematic review," PLoS One, vol. 12, no. 8, article e0182081, 2017.

[27] P. Rys, P. Wojciechowski, A. Rogoz-Sitek et al., "Systematic review and meta-analysis of randomized clinical trials comparing efficacy and safety outcomes of insulin glargine with $\mathrm{NPH}$ insulin, premixed insulin preparations or with insulin detemir in type 2 diabetes mellitus," Acta diabetologica, vol. 52, no. 4, pp. 649-662, 2015.

[28] A. McGovern, Z. Tippu, W. Hinton, N. Munro, M. Whyte, and S. de Lusignan, "Comparison of medication adherence and persistence in type 2 diabetes: a systematic review and meta-analysis," Diabetes, obesity \& metabolism., vol. 20, no. 4, pp. 1040-1043, 2018.

[29] U. Pedersen-Bjergaard, P. L. Kristensen, H. Beck-Nielsen et al., "Effect of insulin analogues on risk of severe hypoglycaemia in patients with type 1 diabetes prone to recurrent severe hypoglycaemia (HypoAna trial): a prospective, randomised, open-label, blinded-endpoint crossover trial," The lancet Diabetes \& endocrinology., vol. 2, no. 7, pp. 553-561, 2014.

[30] T. Semlitsch, J. Engler, A. Siebenhofer, K. Jeitler, A. Berghold, and K. Horvath, "(Ultra-)long-acting insulin analogues versus NPH insulin (human isophane insulin) for adults with type 2 diabetes mellitus," The Cochrane database of systematic reviews, vol. 11, p. Cd005613, 2020.

[31] P. Almeida, T. B. C. Silva, F. de Assis Acurcio et al., "Quality of life of patients with type 1 diabetes mellitus using insulin analog glargine compared with NPH insulin: a systematic review and policy implications," The patient., vol. 11, no. 4, pp. 377-389, 2018.

[32] B. Hemmingsen, M. I. Metzendorf, and B. Richter, "(Ultra)long-acting insulin analogues for people with type 1 diabetes mellitus," The Cochrane database of systematic reviews, vol. 3 , p. Cd013498, 2021.

[33] A. L. Caires de Souza, F. A. Acurcio, A. A. Guerra Júnior, R. C. Rezende Macedo do Nascimento, B. Godman, and L. M. Diniz, "Insulin glargine in a Brazilian state: should the government disinvest? An assessment based on a systematic review," Applied health economics and health policy., vol. 12, no. 1, pp. 19-32, 2014.

[34] A. C. Tricco, H. M. Ashoor, J. Antony et al., "Comparative efficacy and safety of ultra-long-acting, long-acting, intermediate-acting, and biosimilar insulins for type 1 diabetes 
mellitus: a systematic review and network meta-analysis," Journal of General Internal Medicine, vol. 36, no. 8, pp. 2414-2426, 2021.

[35] M. Ewen, H. J. Joosse, D. Beran, and R. Laing, "Insulin prices, availability and affordability in 13 low-income and middleincome countries," BMJ global health., vol. 4, no. 3, article e001410, 2019.

[36] D. Beran, M. Ewen, and R. Laing, "Constraints and challenges in access to insulin: a global perspective," The lancet Diabetes \& endocrinology., vol. 4, no. 3, pp. 275-285, 2016.

[37] M. Haque, S. Islam, Z. M. Kamal et al., "Ongoing efforts to improve the management of patients with diabetes in Bangladesh and the implications," Hospital practice., pp. 1-7, 2021.

[38] Zion Market Research, Insulin glargine market: by type (prefilled syringe and single dose vial), by application (type 1 diabetes and type 2 diabetes), by distribution channel (hospital pharmacy, online sales, retail pharmacy and other distribution channels): global industry perspective, comprehensive analysis and forecast, pp. 2018-2025, 2019, https://www .zionmarketresearch.com/report/insulin-glargin-market.

[39] "Research and Markets," \$24 billion insulin markets - global intelligence database 2012-2018 \& 2019-2023, 2019, https:// www.globenewswire.com/news-release/2019/05/29/ $1856512 / 0 /$ en/24-Billion-Insulin-Markets-GlobalIntelligence-Database-2012-2018-2019-2023.html.

[40] PMLive, Levemirhttp://www.pmlive.com/top_pharma_list/ pharmaceutical_products/levemir.

[41] A. Y. Y. Cheng, J. Wong, N. Freemantle, S. H. Acharya, and E. Ekinci, "The safety and efficacy of second-generation basal insulin analogues in adults with type 2 diabetes at risk of hypoglycemia and use in other special populations: a narrative review," Diabetes therapy., vol. 11, no. 11, pp. 25552593, 2020.

[42] N. Thalange, J. Gundgaard, W. Parekh, and D. Tutkunkardas, "Cost analysis of insulin degludec in comparison with insulin detemir in treatment of children and adolescents with type 1 diabetes in the UK," BMJ open diabetes research \& care., vol. 7, no. 1, article e000664, 2019.

[43] M. Evans, R. G. J. Moes, K. S. Pedersen, J. Gundgaard, and T. R. Pieber, "Cost-effectiveness of insulin degludec versus insulin glargine U300 in the Netherlands: evidence from a randomised controlled trial," Advances in Therapy, vol. 37, no. 5, pp. 2413-2426, 2020.

[44] M. Russel-Szymczyk, V. Valov, A. Savova, and M. Manova, "Cost-effectiveness of insulin degludec versus insulin glargine U100 in adults with type 1 and type 2 diabetes mellitus in Bulgaria," BMC endocrine disorders, vol. 19, no. 1, p. 132, 2019.

[45] U. Permsuwan, K. Thavorn, P. Dilokthornsakul, S. Saokaew, and N. Chaiyakunapruk, "Cost-effectiveness of insulin detemir versus insulin glargine for Thai type 2 diabetes from a payer's perspective," Journal of Medical Economics, vol. 20, no. 9, pp. 991-999, 2017.

[46] D. Beran, M. Lazo-Porras, C. M. Mba, and J. C. Mbanya, "A global perspective on the issue of access to insulin," Diabetologia, vol. 64, no. 5, pp. 954-962, 2021.

[47] A. A. Shafie and C. H. Ng, "Cost-effectiveness of insulin glargine and insulin detemir in the basal regimen for naïve insulin patients with type 2 diabetes mellitus (T2DM) in Malaysia," ClinicoEconomics and outcomes research., vol. Volume 12, pp. 333-343, 2020.
[48] J. Jendle, Å. Ericsson, B. Ekman et al., "Real-world costeffectiveness of insulin degludec in type 1 and type 2 diabetes mellitus from a Swedish 1-year and long-term perspective," Journal of Medical Economics, vol. 23, no. 11, pp. 13111320, 2020.

[49] T. Y. Lee, S. Kuo, C. Y. Yang, and H. T. Ou, "Cost-effectiveness of long-acting insulin analoguesvsintermediate/longacting human insulin for type 1 diabetes: a populationbased cohort followed over 10 years," British journal of clinical pharmacology., vol. 86, no. 5, pp. 852-860, 2020.

[50] B. Alemayehu, J. Speiser, L. Bloudek, and E. Sarnes, "Costs associated with long-acting insulin analogues in patients with diabetes," The American journal of managed care, vol. 24, 2018.

[51] S. Gururaj Setty, W. Crasto, J. Jarvis, K. Khunti, and M. J. Davies, "New insulins and newer insulin regimens: a review of their role in improving glycaemic control in patients with diabetes," Postgraduate Medical Journal, vol. 92, no. 1085, pp. 152-164, 2016.

[52] T. B. Jensen, S. C. Kim, E. Jimenez-Solem, D. Bartels, H. R. Christensen, and J. T. Andersen, "Shift from adalimumab originator to biosimilars in Denmark," JAMA Internal Medicine., vol. 180, no. 6, pp. 902-903, 2020.

[53] W. Matusewicz, B. Godman, H. B. Pedersen et al., "Improving the managed introduction of new medicines: sharing experiences to aid authorities across Europe," Expert review of pharmacoeconomics \& outcomes research., vol. 15, no. 5, pp. 755-758, 2015.

[54] K. Davio, After biosimilar deals, UK spending on adalimumab will drop by 75\%, 2018, https://www.centerforbiosimilars .com/news/after-biosimilar-deals-uk-spending-onadalimumab-will-drop-by-75.

[55] E. Moorkens, B. Godman, I. Huys et al., "The expiry of Humira $^{\circledR}$ market exclusivity and the entry of adalimumab biosimilars in Europe: an overview of pricing and national policy measures," Frontiers in pharmacology, vol. 11, 2021.

[56] B. Godman, "Biosimilars are becoming indispensable in the management of multiple diseases although concerns still exist," Bangladesh Journal of Medical Science., vol. 20, no. 1, pp. 5-10, 2020.

[57] T. Yamada, R. Kamata, K. Ishinohachi et al., "Biosimilar vs originator insulins: systematic review and meta-analysis," Diabetes, obesity \& metabolism., vol. 20, no. 7, pp. 17871792, 2018.

[58] J. J. Altman, N. Chevalier, B. Delemer, F. Travert, and I. Benabbad, "LY2963016 insulin glargine: the first biosimilar insulin approved in the European Union," Presse Médicale, vol. 47, no. 10, pp. 854-866, 2018.

[59] T. C. Blevins, A. Barve, B. Sun et al., "Efficacy and safety of MYL-1501D versus insulin glargine in patients with type 2 diabetes after 24 weeks: results of the phase III INSTRIDE 2 study," Diabetes, obesity \& metabolism., vol. 21, no. 1, pp. 129-135, 2019.

[60] T. C. Blevins, A. Barve, Y. Raiter et al., "Efficacy and safety of MYL-1501D versus insulin glargine in people with type 1 diabetes mellitus: results of the INSTRIDE 3 phase 3 switch study," Diabetes, obesity \& metabolism., vol. 22, no. 3, pp. 365-372, 2020.

[61] S. M. Hoy, "MYL1501D insulin glargine: a review in diabetes mellitus," BioDrugs, vol. 34, no. 2, pp. 245-251, 2020.

[62] Greater Glasgow, "Greater Glasgow and Clyde," Clyde. Medicines Update - Semglee ${ }^{\circledR}$ - preferred brand of insulin glargine, 
2020, http://ggcprescribing.org.uk/blog/alternatives-insulinglargine-post-tc/.

[63] M. Greener, "Why isn't the NHS making the most of biosimilar insulin?," Prescriber, vol. 30, no. 8, pp. 21-24, 2019.

[64] Greater Glasgow, Clyde. Medicines Update - Prescribing medicines by brand, 2020, http://www.ggcprescribing.org.uk/ blog/prescribing-medicines-brand/.

[65] Lothian Formulary, 6.1.1 Insulins, 2020, https://www.ljf.scot .nhs.uk/LothianJointFormularies/Adult/6.0/6.1/6.1.1/Pages/ default.aspx.

[66] WHO, WHO launches first-ever insulin prequalification programme to expand access to life-saving treatment for diabetes, 2019, https://www.who.int/news/item/13-11-2019-wholaunches-first-ever-insulin-prequalification-programme-toexpand-access-to-life-saving-treatment-for-diabetes.

[67] D. Gotham, M. J. Barber, and A. Hill, "Production costs and potential prices for biosimilars of human insulin and insulin analogues," BMJ global health., vol. 3, no. 5, article e000850, 2018.

[68] S. R. Chapman, R. W. Fitzpatrick, and M. I. Aladul, "Knowledge, attitude and practice of healthcare professionals towards infliximab and insulin glargine biosimilars: result of a UK web-based survey," BMJ Open, vol. 7, no. 6, article e016730, 2017.

[69] I. Agirrezabal, E. Sánchez-Iriso, K. Mandar, and J. M. Cabasés, "Real-world budget impact of the adoption of insulin glargine biosimilars in primary care in England (20152018)," Diabetes Care, vol. 43, no. 8, pp. 1767-1773, 2020

[70] E. Standl and D. R. Owen, "New long-acting basal insulins: does benefit outweigh cost?," Diabetes Care, vol. 39, Supplement 2, pp. S172-S179, 2016.

[71] J. Escalada, F. Bonnet, J. Wu et al., "Reduced hypoglycemia risk in type 2 diabetes patients switched to/initiating insulin glargine 300 vs $100 \mathrm{U} / \mathrm{ml}$ : a European real-world study," Advances in Therapy, vol. 37, no. 9, pp. 3863-3877, 2020.

[72] A. Díez-Fernández, I. Cavero-Redondo, J. Moreno-Fernández, D. P. Pozuelo-Carrascosa, M. Garrido-Miguel, and V. Martínez-Vizcaíno, "Effectiveness of insulin glargine U300 versus insulin glargine $U-100$ on nocturnal hypoglycemia and glycemic control in type 1 and type 2 diabetes: a systematic review and meta-analysis," Acta diabetologica., vol. 56, no. 3, pp. 355-364, 2019.

[73] G. B. Bolli, M. C. Riddle, R. M. Bergenstal et al., "New insulin glargine $300 \mathrm{U} / \mathrm{ml}$ compared with glargine $100 \mathrm{U} / \mathrm{ml}$ in insulin-naïve people with type 2 diabetes on oral glucoselowering drugs: a randomized controlled trial (EDITION 3)," Diabetes, obesity \& metabolism., vol. 17, no. 4, pp. 386394, 2015.

[74] A. Abitbol, R. E. Brown, D. Jiandani, L. Sauriol, and R. Aronson, "Real-world health outcomes of insulin glargine $300 \mathrm{U} / \mathrm{mL}$ vs insulin glargine $100 \mathrm{U} / \mathrm{mL}$ in adults with type 1 and type 2 diabetes in the Canadian LMC Diabetes Patient Registry: the REALITY Study," Canadian journal of diabetes, vol. 43, no. 7, 2019.

[75] R. Ritzel, R. Roussel, A. Giaccari, J. Vora, C. Brulle-Wohlhueter, and $\mathrm{H}$. Yki-Järvinen, "Better glycaemic control and less hypoglycaemia with insulin glargine $300 \mathrm{U} / \mathrm{mL}$ vs glargine $100 \mathrm{U} / \mathrm{mL}$ : 1-year patient-level meta-analysis of the EDITION clinical studies in people with type 2 diabetes," Diabetes, obesity \& metabolism., vol. 20, no. 3, pp. 541548, 2018.
[76] H. Vargas-Uricoechea, "Efficacy and Safety of Insulin Glargine $300 \mathrm{U} / \mathrm{mL}$ versus $100 \mathrm{U} / \mathrm{mL}$ in Diabetes Mellitus: A Comprehensive Review of the Literature," Journal of diabetes research., vol. 2018, article 2052101, pp. 1-28, 2018.

[77] K. Keramatian, T. Chakrabarty, and L. N. Yatham, "Longacting injectable second-generation/atypical antipsychotics for the management of bipolar disorder: a systematic review," CNS Drugs, vol. 33, no. 5, pp. 431-456, 2019.

[78] A. T. Olagunju, S. R. Clark, and B. T. Baune, "Long-acting atypical antipsychotics in schizophrenia: a systematic review and meta-analyses of effects on functional outcome," The Australian and New Zealand journal of psychiatry., vol. 53, no. 6, pp. 509-527, 2019.

[79] B. Godman, M. Persson, J. Miranda et al., "Can authorities take advantage of the availability of generic atypical antipsychotic drugs? Findings from Sweden and potential implications," Journal of Pharmaceutical Health Services Research, vol. 4, no. 3, pp. 139-150, 2013.

[80] H. McCabe, B. Godman, A. Kurdi et al., "Prescribing trends of inhaler treatments for asthma and chronic obstructive pulmonary disease within a resource-constrained environment in the Scottish national health service: findings and implications," Expert review of respiratory medicine., vol. 13, no. 7, pp. 679-689, 2019.

[81] A. A. Alkhafaji, L. Trinquart, G. Baron, M. Desvarieux, and P. Ravaud, "Impact of evergreening on patients and health insurance: a meta analysis and reimbursement cost analysis of citalopram/escitalopram antidepressants," BMC medicine, vol. 10, no. 1, 2012.

[82] N. Vernaz, G. Haller, F. Girardin et al., "Patented drug extension strategies on healthcare spending: a cost-evaluation analysis," PLoS Medicine, vol. 10, no. 6, article e1001460, 2013.

[83] B. Godman, A. Kurdi, H. McCabe et al., "Ongoing initiatives within the Scottish national health service to affect the prescribing of selective serotonin reuptake inhibitors and their influence," Journal of comparative effectiveness research., vol. 8, no. 7, pp. 535-547, 2019.

[84] B. Godman, A. Kurdi, H. McCabe et al., "Ongoing activities to influence the prescribing of proton pump inhibitors within the Scottish national health service: their effect and implications," Generics and Biosimilars Initiative Journal., vol. 7, no. 4, pp. 142-151, 2018.

[85] B. Godman, M. Wilcock, A. Martin et al., "Generic pregabalin; current situation and implications for health authorities, generics and biosimilars manufacturers in the future," GaBI Journal., vol. 4, no. 3, pp. 125-135, 2015.

[86] Scottish Medicines Consortium, Insulin glargine 300 units/mL solution for injection in a pre-filled pen (Toujeo ${ }^{\circledR}$ ), 2015, https://www.scottishmedicines.org.uk/media/1860/ insulin_glargine_toujeo_solostar_abbreviated_final_july_ 2015_for_website.pdf.

[87] H. H. P. Kluge, K. Wickramasinghe, H. L. Rippin et al., "Prevention and control of non-communicable diseases in the COVID-19 response," Lancet, vol. 395, no. 10238, pp. 1678-1680, 2020.

[88] O. O. Ogunleye, D. Basu, D. Mueller et al., "Response to the novel corona virus (COVID-19) pandemic across Africa: successes, challenges, and implications for the future," Frontiers in pharmacology, vol. 11, no. 1205, 2020.

[89] B. Godman, A. Hill, S. Simoens et al., "Pricing of oral generic cancer medicines in 25 European countries; findings and 
implications," Generics and Biosimilars Initiative Journal., vol. 8, no. 2, pp. 49-70, 2019.

[90] B. Godman, W. Shrank, M. Andersen et al., "Policies to enhance prescribing efficiency in Europe: findings and future implications," Frontiers in pharmacology., vol. 1, 2011.

[91] L. Vončina, T. Strizrep, B. Godman et al., "Influence of demand-side measures to enhance renin-angiotensin prescribing efficiency in Europe: implications for the future," Expert review of pharmacoeconomics \& outcomes research., vol. 11, no. 4, pp. 469-479, 2011.

[92] D. C. Baumgart, L. Misery, S. Naeyaert, and P. C. Taylor, "Biological therapies in immune-mediated inflammatory diseases: can biosimilars reduce access inequities?," Frontiers in pharmacology., vol. 10, p. 279, 2019.

[93] M. Kostic, L. Djakovic, R. Sujic, B. Godman, and S. M. Jankovic, "Inflammatory bowel diseases (Crohn's disease and ulcerative colitis): cost of treatment in Serbia and the implications," Applied health economics and health policy., vol. 15, no. 1, pp. 85-93, 2017.

[94] M. Péntek, P. L. Lakatos, T. Oorsprong et al., "Access to biologicals in Crohn's disease in ten European countries," World Journal of Gastroenterology, vol. 23, no. 34, pp. 6294-6305, 2017.

[95] P. Putrik, S. Ramiro, T. K. Kvien et al., "Inequities in access to biologic and synthetic DMARDs across 46 European countries," Annals of the rheumatic diseases., vol. 73, no. 1, pp. 198-206, 2014.

[96] F. Rencz, M. Péntek, M. Bortlik et al., "Biological therapy in inflammatory bowel diseases: access in Central and Eastern Europe," World Journal of Gastroenterology, vol. 21, no. 6, pp. 1728-1737, 2015.

[97] D. Beran, R. O. Laing, W. Kaplan et al., "A perspective on global access to insulin: a descriptive study of the market, trade flows and prices," Diabetic medicine., vol. 36, no. 6, pp. 726-733, 2019.

[98] S. Vogler and P. Schneider, "Assessing data sources for medicine price studies," International journal of technology assessment in health care., vol. 35, no. 2, pp. 106-115, 2019.

[99] K. Garuoliene, B. Godman, J. Gulbinovic, K. Schiffers, and B. Wettermark, "Differences in utilization rates between commercial and administrative databases: implications for future health-economic and cross-national studies," Expert review of pharmacoeconomics \& outcomes research., vol. 16, no. 2, pp. 149-152, 2016.

[100] WHO, "WHO Collaborating Centre for Drug Statistics Methodology," ATC/ DDD Indexhttps://www.whocc.no/.

[101] WHO, "WHO Collaborating Centre for Drug Statistics Methodology," Guidelines for ATC classification and DDD assignment, 2021, https://www.whocc.no/filearchive/ publications/2021_guidelines_web.pdf.

[102] H. Neville and S. C. Trenaman, "Drug utilization research: methods and applications," The Canadian journal of hospital pharmacy, vol. 70, no. 4, p. 325, 2017.

[103] S. Gupta, H. Wang, N. Skolnik et al., "Treatment dosing patterns and clinical outcomes for patients with type 2 diabetes starting or switching to treatment with insulin glargine (300 units per milliliter) in a real-world setting: a retrospective observational study," Advances in Therapy, vol. 35, no. 1, pp. 43-55, 2018.

[104] J. C. Moon, B. Godman, M. Petzold et al., "Different initiatives across Europe to enhance losartan utilization post generics: impact and implications," Frontiers in pharmacology., vol. 5, 2014.

[105] B. Godman, M. Petzold, K. Bennett et al., "Can authorities appreciably enhance the prescribing of oral generic risperidone to conserve resources? Findings from across Europe and their implications," Medicine, vol. 12, no. 1, 2014.

[106] B. Godman, W. Shrank, M. Andersen et al., "Comparing policies to enhance prescribing efficiency in Europe through increasing generic utilization: changes seen and global implications," Expert review of pharmacoeconomics \& outcomes research., vol. 10, no. 6, pp. 707-722, 2010.

[107] B. Godman, I. Bishop, A. E. Finlayson, S. Campbell, H. Y. Kwon, and M. Bennie, "Reforms and initiatives in Scotland in recent years to encourage the prescribing of generic drugs, their influence and implications for other countries," Expert review of pharmacoeconomics \& outcomes research., vol. 13, no. 4, pp. 469-482, 2013.

[108] B. Tubic, V. Markovic-Pekovic, S. Jungić, E. Allocati, and B. Godman, "Availability and accessibility of monoclonal antibodies in Bosnia and Herzegovina: findings and implications," Medicine Access@Point of Care., vol. 5, p. 239920262110276, 2021.

[109] P. Vella Bonanno, M. Ermisch, B. Godman et al., “Adaptive pathways: possible next steps for payers in preparation for their potential implementation," Frontiers in pharmacology, vol. 8, p. 497, 2017.

[110] A. Ferrario, D. Arāja, T. Bochenek et al., "The implementation of managed entry agreements in Central and Eastern Europe: findings and implications," PharmacoEconomics, vol. 35, no. 12, pp. 1271-1285, 2017.

[111] T. Bochenek, V. Abilova, A. Alkan et al., "Systemic Measures and Legislative and Organizational Frameworks Aimed at Preventing or Mitigating Drug Shortages in 28 European and Western Asian Countries," Frontiers in pharmacology., vol. 8, 2018.

[112] C. Pontes, C. Zara, J. Torrent-Farnell et al., "Time to review authorisation and funding for new cancer medicines in Europe? Inferences from the case of olaratumab," Applied health economics and health policy., vol. 18, no. 1, pp. 5-16, 2020.

[113] B. Godman, M. Haque, S. Kumar et al., "Current utilization patterns for long-acting insulin analogues including biosimilars among selected Asian countries and the implications for the future," Current medical research and opinion., pp. 1-17, 2021.

[114] M. Haque, S. Kumar, J. Charan et al., "Utilisation, availability and price changes of medicines and protection equipment for COVID-19 Among Selected Regions in India: findings and implications," Frontiers in pharmacology, vol. 11, no. 1822, 2021.

[115] B. Godman, M. Haque, S. Islam et al., "Rapid assessment of price instability and paucity of Medicines and protection for COVID-19 across Asia: findings and public health implications for the future," Frontiers in Public Health, vol. 8, no. $744,2020$.

[116] M. Gad, A. Salem, W. Oortwijn, R. Hill, and B. Godman, "Mapping of current obstacles for rationalizing use of medicines (CORUM) in Europe: current situation and potential solutions," Frontiers in pharmacology, vol. 11, no. 144, 2020.

[117] NHS Scotland, Quality Prescribing for Diabetes - A Guide for Improvement 2018 - 2021, 2018, https://www.therapeutics 
.scot.nhs.uk/wp-content/uploads/2018/03/StrategyDiabetes-Quality-Prescribing-for-Diabetes-2018.pdf.

[118] A. Leporowski, B. Godman, A. Kurdi et al., "Ongoing activities to optimize the quality and efficiency of lipid-lowering agents in the Scottish national health service: influence and implications," Expert review of pharmacoeconomics \& outcomes research., vol. 18, no. 6, pp. 655-666, 2018.

[119] B. Godman, M. Persson, J. Miranda et al., "Changes in the utilization of venlafaxine after the introduction of generics in Sweden," Applied health economics and health policy., vol. 11, no. 4, pp. 383-393, 2013.

[120] B. Godman, B. Wettermark, J. Miranda, M. Bennie, A. Martin, and R. E. Malmstrom, "Influence of multiple initiatives in Sweden to enhance ARB prescribing efficiency following generic losartan; findings and implications for other countries," International journal of clinical practice., vol. 67, no. 9, pp. 853-862, 2013.

[121] K. Garuoliene, B. Godman, J. Gulbinovic, B. Wettermark, and A. Haycox, "European countries with small populations can obtain low prices for drugs: Lithuania as a case history," Expert review of pharmacoeconomics \& outcomes research., vol. 11, no. 3, pp. 343-349, 2011.

[122] B. Godman, B. Wettermark, M. van Woerkom et al., "Multiple policies to enhance prescribing efficiency for established medicines in Europe with a particular focus on demandside measures: findings and future implications," Frontiers in pharmacology., vol. 5, 2014.

[123] V. Marković-Peković, R. Škrbić, A. Petrović et al., "Polypharmacy among the elderly in the Republic of Srpska: extent and implications for the future," Expert review of pharmacoeconomics \& outcomes research., vol. 16, no. 5, pp. 609-618, 2016.

[124] IQVIA, The Impact of Biosimilar Competition in Europe, 2019, https://ec.europa.eu/docsroom/documents/38461.

[125] A. Harsanyi, M. Csanadi, K. Marky, A. Z. Vincziczki, Z. Kalo, and A. Inotai, "Influence of biosimilar infliximab launch on the utilization pattern of biological medicines: the case of Hungary," Expert review of pharmacoeconomics \& outcomes research., vol. 20, no. 6, pp. 653-659, 2020.

[126] P. Kawalec, E. Stawowczyk, T. Tesar et al., "Pricing and Reimbursement of Biosimilars in Central and Eastern European Countries," Frontiers in pharmacology., vol. 8, p. 288, 2017.

[127] A. Bertolani and C. Jommi, "Local policies on biosimilars: are they designed to optimize use of liberated resources?," Generics and Biosimilars Journal (GaBI)., vol. 9, no. 4, pp. 163-170, 2020.

[128] B. Godman, E. Allocati, E. Moorkens, and H.-Y. Kwon, "Can local policies on biosimilars optimize the use of freed resources - experiences from Italy," Generics and Biosimilars Initiative Journal (GABI)., vol. 9, no. 4, pp. 183-187, 2020.

[129] R. E. Ferner, W. Lenney, and J. F. Marriott, "Controversy over generic substitution,” BMJ, vol. 340, no. jun01 1, p. c2548, 2010.

[130] IQVIA, Country Scorecards for Biosimilar Sustainability, 2020, https://www.iqvia.com/-/media/iqvia/pdfs/institutereports/country-scorecards-for-biosimilar-sustainability/ iqvia-institute-scorecards-appendix-orb2520.pdf?la=en.

[131] V. Singh, Top biosimilar companies with approved and pipeline products in the US and EU, 2019, https://pharmashots .com/24011/top-biosimilar-companies-with-approved-andpipeline-products-in-the-us-and-eu/.

[132] S. A. Schreiber and A. Russmann, "Long-term efficacy of insulin glargine therapy with an educational programme in type 1 diabetes patients in clinical practice," Current medical research and opinion., vol. 23, no. 12, pp. 31313136, 2007.

[133] M. Woerkom, H. Piepenbrink, B. Godman et al., "Ongoing measures to enhance the efficiency of prescribing of proton pump inhibitors and statins in The Netherlands: influence and future implications," Journal of comparative effectiveness research., vol. 1, no. 6, pp. 527-538, 2012.

[134] P. Dylst and S. Simoens, "Does the market share of generic medicines influence the price level?: a European analysis," PharmacoEconomics, vol. 29, no. 10, pp. 875-882, 2011.

[135] U. Hesse, B. Godman, M. Petzold, A. Martin, and R. E. Malmstrom, "Impact of delisting ARBs, apart from losartan, on ARB utilisation patterns in Denmark: implications for other countries," Applied health economics and health policy., vol. 11, no. 6, pp. 677-685, 2013.

[136] J. Fürst, M. Čižman, J. Mrak et al., "The influence of a sustained multifaceted approach to improve antibiotic prescribing in Slovenia during the past decade: findings and implications," Expert review of anti-infective therapy., vol. 13, no. 2, pp. 279-289, 2015.

[137] B. Godman, S. Sakshaug, C. Berg, B. Wettermark, and A. Haycox, "Combination of prescribing restrictions and policies to engineer low prices to reduce reimbursement costs," Expert review of pharmacoeconomics \& outcomes research., vol. 11, no. 1, pp. 121-129, 2011.

[138] B. Wettermark, B. Godman, M. Neovius, N. Hedberg, T. O. Mellgren, and T. Kahan, "Initial effects of a reimbursement restriction to improve the cost- effectiveness of antihypertensive treatment," Health Policy, vol. 94, no. 3, pp. 221-229, 2010.

[139] E. Eatwell and A. Swierczyna, "Emerging voluntary cooperation between European healthcare systems: are we facing a new future?," Medicine Access@Point of Care, vol. 3, p. 239920261985231, 2019.

[140] J. F. O’Mahony, “Beneluxa: what are the prospects for collective bargaining on pharmaceutical prices given diverse health technology assessment processes?," PharmacoEconomics, vol. 37, no. 5, pp. 627-630, 2019.

[141] WHO, WHO Guideline on Country Pharmaceutical Pricing Policies, World Health Organization, Geneva, second edition, 2020, https://apps.who.int/iris/bitstream/handle/10665/ 335692/9789240011878-eng.pdf.

[142] S. Singh, Biocon's Malaysia insulin glargine manufacturing facility receives EU GMP certification, 2019, https:// indiamedtoday.com/biocons-malaysia-insulin-glarginemanufacturing-facility-receives-eu-gmp-certification/.

[143] S. Opanga, L. W. Njeri, D. Kimonge, B. Godman, and M. Oluka, "Assessing utilisation and expenditure on longacting insulin analogues in Kenya; findings and implications for the future," Scholars Academic Journal of Pharmacy, vol. 10, no. 4, pp. 63-70, 2021.

[144] Department of Health Republic of South Africa, National Essential Medicines List Committee (NEMLC) - Tertiary and Quaternary Level Essential Medicines List Reviewed Items, 2021, https://www.knowledgehub.org.za/system/files/ elibdownloads/2021-04/Tertiary\%20and\%20Quaternary\% 
20Level\%20Essential\%20Medicine\%20Recommendations_ April\%202021.pdf.

[145] D. Beran, M. Ewen, K. Lipska, I. B. Hirsch, and J. S. Yudkin, "Availability and affordability of essential medicines: implications for global diabetes treatment," Current diabetes reports., vol. 18 , no. $8,2018$.

[146] B. Godman, J. Fadare, H. Y. Kwon et al., "Evidence-based public policy making for medicines across countries: findings and implications for the future," Journal of comparative effectiveness research., vol. 10, no. 12, pp. 1019-1052, 2021. 